\title{
Lächeln Sie mit!
}

_Ein indisches Sprichwort besagt: „Das Lächeln, das du aussendest, kehrt immer zu dir zurück. “ Wir wagen in dieser Ausgabe den Selbstversuch und möchten Sie an unserer Freude teilhaben lassen. ergopraxis feiert Geburtstag, was uns - wie Sie unten sehen können - gut gelaunt in den Wonnemonat Mai starten lässt.

_ Sie, liebe Leser, schenken uns oft ein Lächeln. Und zwar durch die vielen positiven Rückmeldungen, die wir in den letzten zwei Jahren von Ihnen erhalten haben! Oder durch die vielen spannenden Gespräche, die wir telefonisch oder persönlich auf Veranstaltungen mit Ihnen geführt haben.

Bleiben Sie uns weiterhin treu! Für Ihre Anregungen und Wünsche haben wir immer ein offenes Ohr!

Mit sonnigen Grüßen von Ihrer

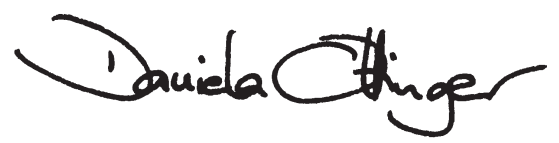

PS: In dieser Ausgabe warten einige Gewinne auf Sie. Holen Sie sich also schnell eines unserer „Geburtstagsgeschenke“ ab unter www.thieme.de/ ergoonline > „ergopraxis“ > „Gewinnspiel“. Wir drücken Ihnen die Daumen!
ZU GEWINNEN

Kursplatz

1 Kurs „Lern- und Spielmittel aus Bambus“"

Seite 45

Bücher

2-mal „Ergotherapie in der Orthopädie, Traumatologie und Rheumatologie“ $\quad$ Seite 26 3-mal „Irre! Wir behandeln die Falschen" Seite 35 1-mal „Heilmittelkatalog“ Seite 38 Und außerdem...

1 Plüschdelfin Seite 32

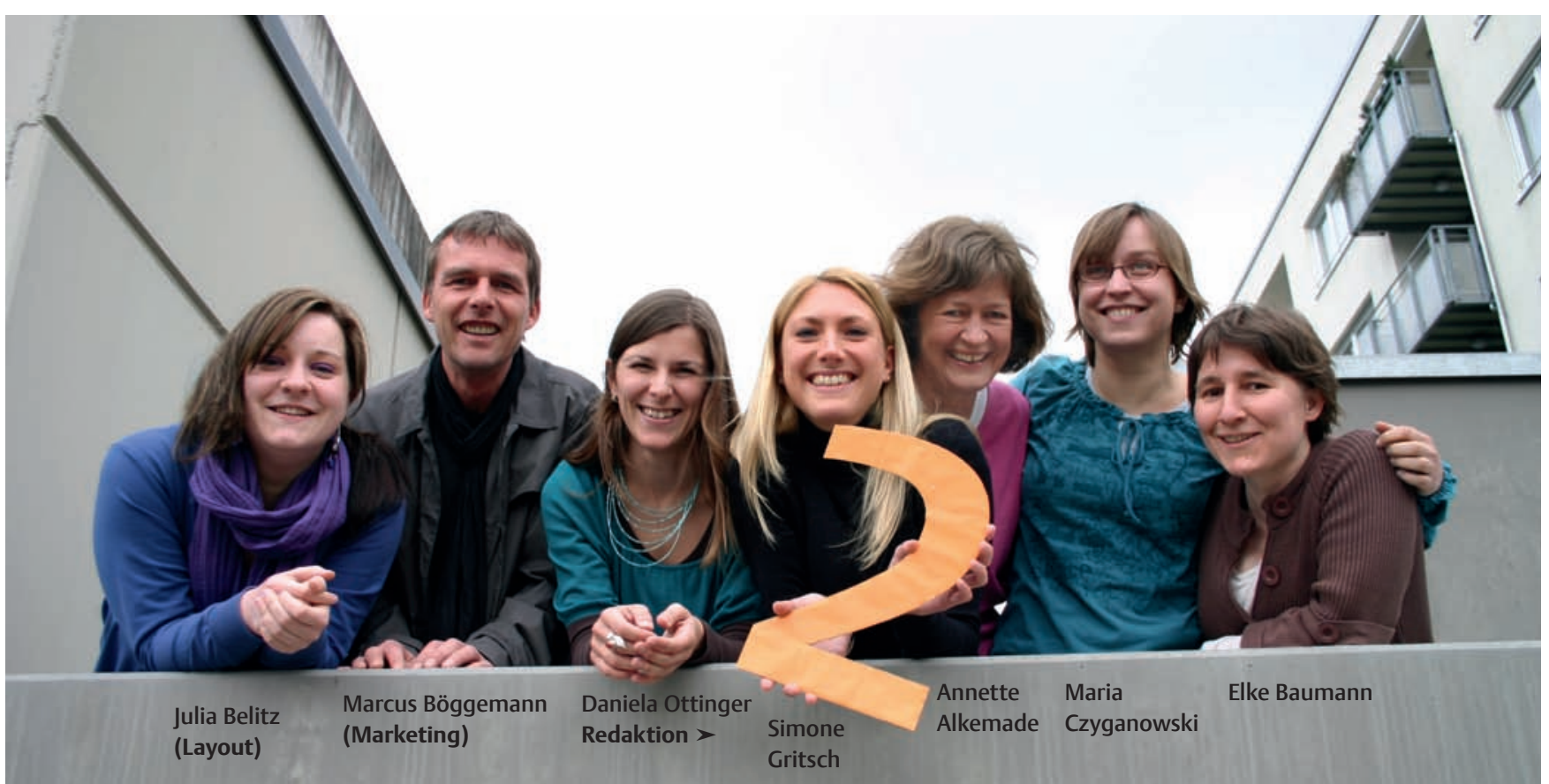

